\title{
Rapid Colchicine Competition-Binding Scintillation Proximity Assay Using Biotin-Labeled Tubulin
}

BioTechniques 29:156-160 (July 2000)

\author{
Stephen K. Tahir, Peter Kovar, \\ Saul H. Rosenberg and \\ Shi-Chung Ng \\ Abbott Laboratories, Abbott \\ Park, IL, USA
}

\section{INTRODUCTION}

Currently, there are several natural products and their analogs with antimitotic activity under development for the treatment of neoplastic diseases (11, 13-15). Colchicine, derived from the plant Colchicum autumnale, was the first antimitotic agent to be characterized. Isolated in the 19th century, it was instrumental in the isolation and characterization of microtubules (11). Microtubules are dynamic, labile, polar polymers composed primarily of tubulin heterodimers consisting of one $\alpha$ and one $\beta$-tubulin subunit noncovalently linked $(3,9,21)$. Microtubules are a major intracellular component of cells involved in cell shape, cellular movement and division $(3,9,12)$. During cell division, microtubules form the mitotic spindle that lines up and properly separates the chromosomes to each new "daughter" cell (26). Compounds such as colchicine interfere with the ability of cells to properly form the mitotic spindle causing the cells to arrest at metaphase. Cells arrested at metaphase with colchicine eventually die by the process of apoptosis $(2,4)$.

The exact mechanism of colchicine on microtubule dynamics is unclear; however, it is known to first bind to a specific site on the $\beta$-tubulin subunit of the tubulin heterodimer. The tubulincolchicine complexes then become incorporated into the microtubule ends, leading to changes in the rate and extent of growing and shortening of microtubules $(14,15,21,27)$. Tubulin- binding assays have been a useful screening tool to identify several new classes of structurally unrelated antimitotic compounds that can interact with tubulin at the colchicine-binding domain. Antimitotic compounds, such as combretastatin A4 and E7010, which bind to tubulin at the colchicine-binding domain, are either under development or in clinical trials as antineoplastic agents $(7,28)$.

Several colchicine-binding assays, such as the DEAE-cellulose filter paper, gel filtration or activated charcoal assays, require the separation of bound colchicine from unbound colchicine $(5,8,18,24)$. However, there are disadvantages to using separation techniques, for example, the introduction of extra steps for separating and washing, plus the potential decay of the complex. A previously developed fluorometric assay does not require the separation of the tubulin-colchicine complex with free colchicine. However, it is not as sensitive as $\left[{ }^{3} \mathrm{H}\right]$ colchicine assays (1). To overcome the disadvantages inherent with separation assays, we developed a novel $\left[{ }^{3} \mathrm{H}\right]$ colchicine competition-binding scintillation proximity assay (SPA) using yttrium beads to evaluate antimitotic compounds in vitro. SPA technology overcomes the disadvantage of traditional filtration techniques because there are no separation steps and the reaction and counting are done in the same well.

This paper describes our novel 96well $\left[{ }^{3} \mathrm{H}\right]$ colchicine SPA using biotinlabeled tubulin and streptavidin-yttrium beads. The assay can be used to identi- 
Table 1. Effect of Various Microtubule Inhibitors on $\left[{ }^{3} \mathbf{H}\right]$ Colchicine Binding to Tubulin

\begin{tabular}{|c|c|c|c|c|}
\hline Compound & Observations & $\underset{(\mu \mathrm{M})}{\mathrm{K}_{\mathrm{i}}}$ & $\begin{array}{c}\text { Reported } \\
\mathrm{K}_{\mathrm{i}}(\mu \mathrm{M})\end{array}$ & $\begin{array}{c}\text { Reference } \\
\text { No. }\end{array}$ \\
\hline Colchicine & competitive inhibition & $0.53 \pm 0.9$ & $0.34-2.0$ & 20 \\
\hline combretastatin A4 & competitive inhibition & $0.18 \pm 0.3$ & 0.12 & 19 \\
\hline E7010 & competitive inhibition & $2.6 \pm 0.2$ & 3.3 & 29 \\
\hline colcemid & competitive inhibition & $4.56 \pm 0.6$ & 14 & 22 \\
\hline mebendazole & competitive inhibition & 2.1 & 3.9 & 23 \\
\hline podophyllotoxin & competitive inhibition & 0.2 & 0.51 & 16 \\
\hline vinblastine & non competitive & - & - & - \\
\hline taxol & non competitive & - & - & - \\
\hline
\end{tabular}

fy novel compounds with potential antimitotic properties that compete with colchicine for the colchicine-binding site on tubulin.

Biotin-labeled tubulin is incubated first with unlabeled compound and radiolabeled ligand (Figure 1). Streptavidin-labeled SPA beads are added, and the radiolabel associated with tubulin is directly counted with no separation step. Our SPA bead method is a powerful tool-it overcomes the disadvantage of traditional filtration techniques because there are no separation steps. It is extremely easy to set up, multiple samples can be assayed and supply and labor costs are reduced as a result of the minimal volume and test reagents used.

\section{MATERIALS AND METHODS}

\section{Chemicals}

Special long-chain, biotin-labeled tubulin was purchased from Cytoskeleton (Denver, CO, USA). $\left[{ }^{3} \mathrm{H}\right]$ colchicine in ethanol [Specific Activity $=2.3$ $\mathrm{TBq} / \mathrm{mmol}(61.4 \mathrm{Ci} / \mathrm{mmol}) ; 1 \mu \mathrm{Ci} / \mu \mathrm{L}]$ was purchased from New England $\mathrm{Nu}$ clear (Boston, MA, USA). Unlabeled colchicine, podophyllotoxin, mebenda-

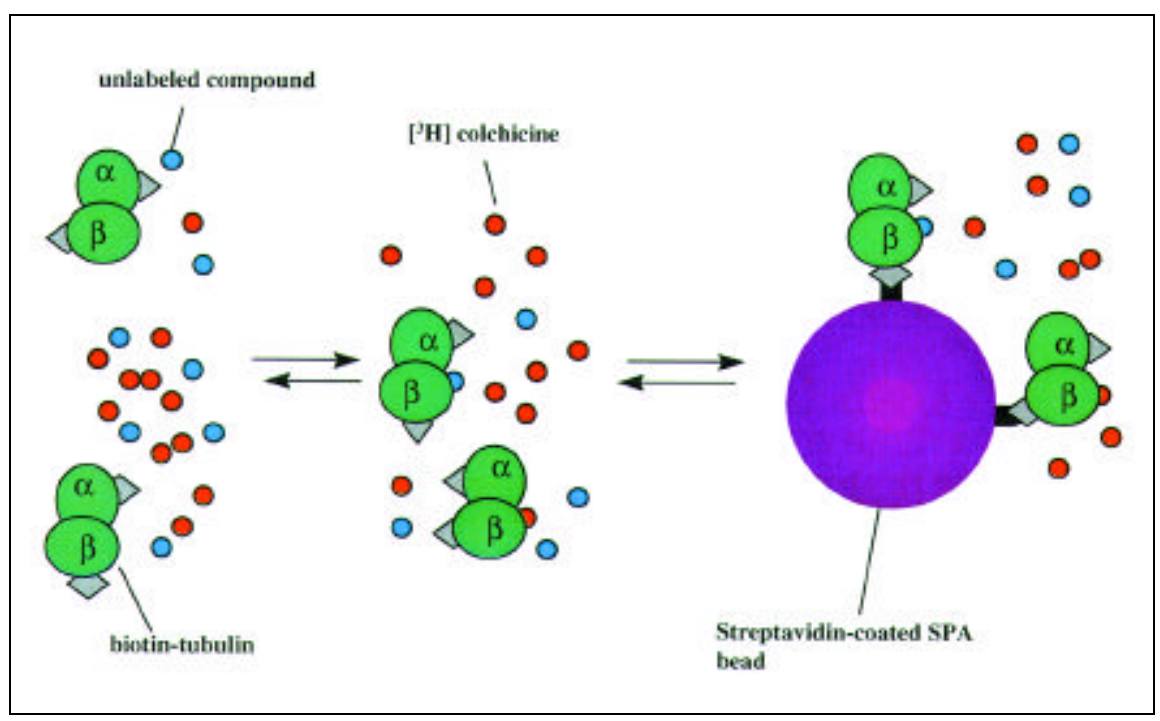

Figure 1. Diagrammatic representation of colchicine-tubulin SPA system. Biotin-labeled tubulin is incubated first with unlabeled compound and radiolabeled ligand. Streptavidin-labeled SPA beads are then added, and the radiolabel associated with tubulin is directly counted without the need to separate bound from free ligand. Any $\left[{ }^{3} \mathrm{H}\right]$ colchicine-tubulin complexes bound to SPA beads will be close enough to stimulate the bead and emit light. Any unbound radioligand is too distant from the bead to transfer energy and therefore is not detected. zole, colcemid, vinblastine and paclitaxel were purchased from Sigma (St. Louis, MO, USA). Combretastatin A4 and E7010 were synthesized at Abbott Laboratories. Unlabeled colchicine, podophyllotoxin, mebendazole, paclitaxel, vinblastine, combretastatin A4 and E7010 were used for the competition-binding assays. Stock solutions of all unlabeled compounds (1 mM) were prepared in ethanol before use.

\section{$\left[{ }^{3} \mathbf{H}\right]$ Colchicine-Tubulin Binding}

Except where noted, radiolabeled colchicine $(0.5 \mu \mathrm{L} ; 1 \mu \mathrm{Ci} / \mu \mathrm{L})$ was first diluted with $19.5 \mu \mathrm{L}$ ethanol for a total transfer volume of $20 \mu \mathrm{L} /$ well (the final concentration of $\left[{ }^{3} \mathrm{H}\right]$ colchicine/well was approximately $0.08 \mu \mathrm{M})$. For $\mathrm{K}_{\mathrm{d}}$ experiments, the appropriate volume of radiolabeled colchicine $(0.03-16 \mu \mathrm{Ci}$ / reaction) was added to a final transfer volume of $20 \mu \mathrm{L} /$ well. Serial dilutions of unlabeled compounds $\left(1 \times 10^{-3}-1 \times\right.$ $\left.10^{-11} \mathrm{M}\right)$ were prepared in ethanol for a total transfer volume of $100 \mu \mathrm{L} /$ well. The radiolabeled colchicine and unlabeled compounds were transferred to a 96-well plate, and the ethanol was evaporated using a SpeedVac ${ }^{\circledR}$ centrifuge for $15 \mathrm{~min}$. The $90-\mu \mathrm{L}$ binding buffer [80 mM PIPES (pH 6.8), 1 mM EGTA, $1 \mathrm{mM} \mathrm{MgCl} 2$ and $1 \mathrm{mM}$ GTP] was added and followed by $0.5 \mu \mathrm{g}$ special long-chain, biotin-labeled tubulin prepared in $10 \mu \mathrm{L}$ binding buffer. The plates were incubated for $2 \mathrm{~h}$ at $37^{\circ} \mathrm{C}$ with gentle shaking. After 2 h, $0.08 \mathrm{mg}$ streptavidin-labeled yttrium SPA beads (Amersham Pharmacia Biotech, Piscat- 
away, NJ, USA) in $20 \mu \mathrm{L}$ binding buffer were added, and the bound radioactivity was determined using a Packard TopCount ${ }^{\mathrm{TM}}$ Microplate Scintillation Counter (Packard Instrument,
Meriden, CT, USA). The cost of the beads on a per-well basis was approximately $\$ 0.16$ (or about \$15/96-well plate). Nonspecific binding was determined in the presence of excess unla-

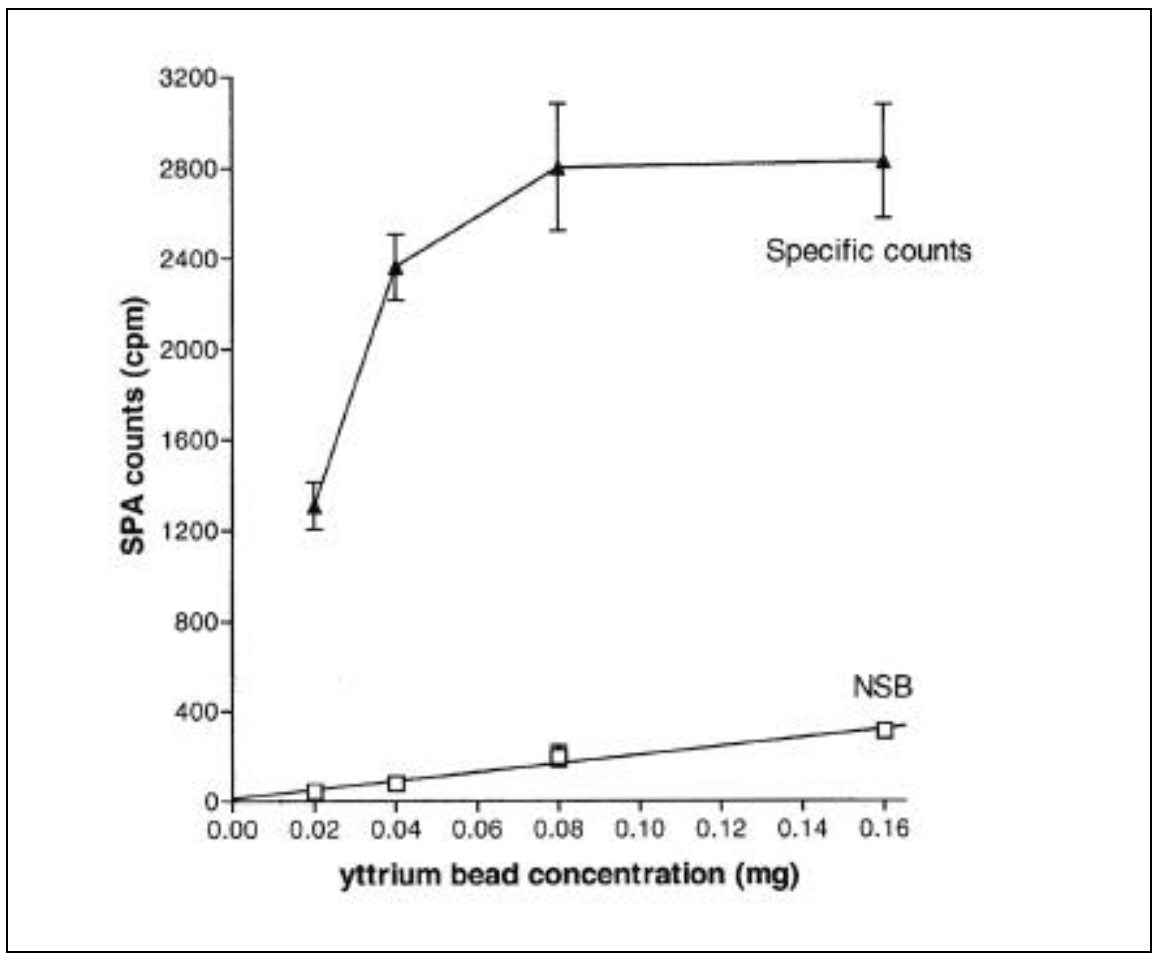

Figure 2. Optimization of bead concentration. Optimal bead concentration was determined by first incubating tubulin with $\left[{ }^{3} \mathrm{H}\right]$ colchicine for $2 \mathrm{~h}$. Various amounts of yttrium beads were added and the specific counts and NSB were determined after 15 min of gentle shaking. Each point represents mean $\pm \operatorname{SD}$ of $n=9$.

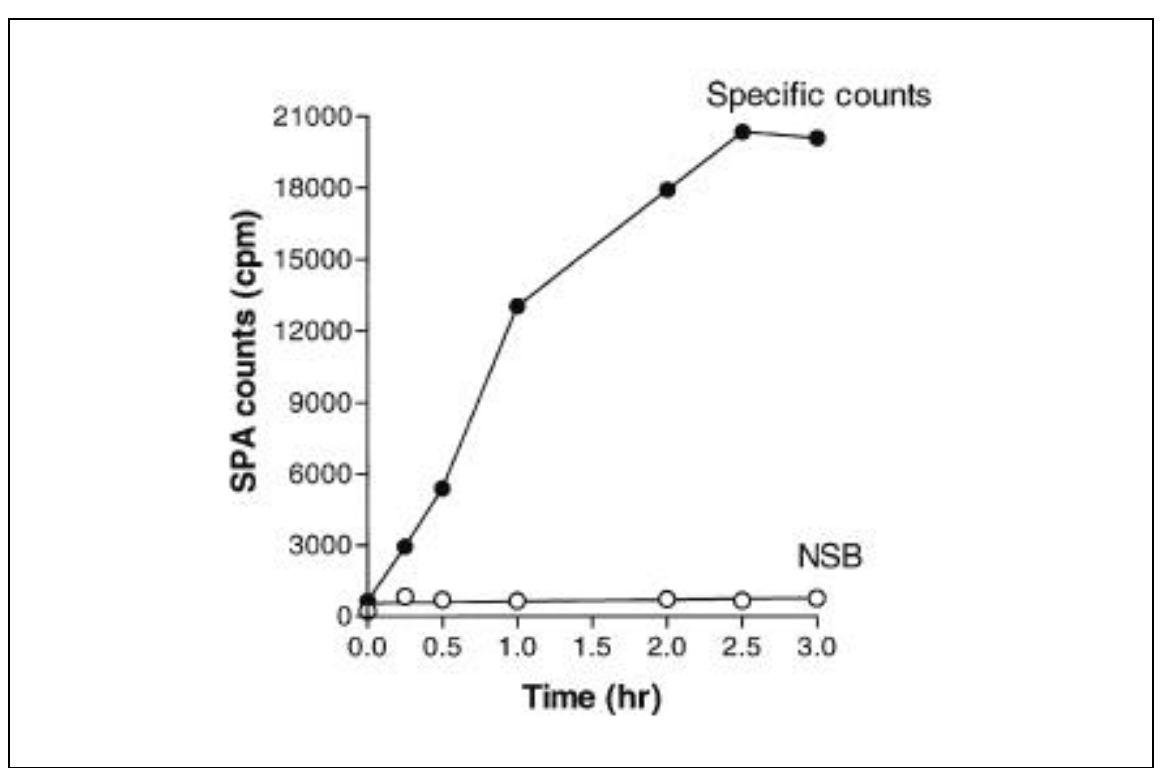

Figure 3. Time course for colchicine binding to tubulin. $\left[{ }^{3} \mathrm{H}\right]$ colchicine $(0.163 \mu \mathrm{M})$ was incubated with biotin-tubulin $(1 \mu \mathrm{g})$ for varying times at $37^{\circ} \mathrm{C}$. The specific and nonspecific counts were determined 15 min after the addition of beads. beled colchicine $\left(>100 \times \mathrm{K}_{\mathrm{d}}\right)$. Nonlinear regression was used to analyze the data using GraphPad Prism ${ }^{\mathrm{TM}}$, Version 2.0.

\section{RESULTS AND DISCUSSION}

\section{Bead Concentration}

The optimal bead concentration to obtain the maximum specific signal with low nonspecific background (NSB) was determined by adding varying amounts of yttrium beads to a fixed amount of $\left[{ }^{3} \mathrm{H}\right]$ colchicine and tubulin. As Figure 2 shows, the specific signal increased linearly and became saturated above $0.08 \mathrm{mg} /$ well. The NSB increased linearly from 0.01 to $0.16 \mathrm{mg} /$ well. We chose $0.08 \mathrm{mg} /$ well as our optimal bead concentration because it gave us a high specific signal while still having a low NSB (5\%). Given the low NSB, our assay is suitable for high-throughput screening. Assays having a specific binding component of greater than $80 \%$ are suitable for high-volume screening because they are reproducible and reliable as drug discovery tools (25).

\section{Incubation Time}

We examined the binding characteristics of colchicine to tubulin over time at $37^{\circ} \mathrm{C}$. Colchicine was shown previously to reversibly bind to tubulin in a two-step manner involving a fast initial binding phase of relatively low affinity followed by a slow conformational change of the complex $(10,17,20)$. As previously described, we observed that colchicine binding to tubulin was biphasic using our SPA system. Our data corroborates the results of Luyckx et al. (20) in that there was a relatively quick phase in which approximately $60 \%$ of the binding occurred, followed by a slower phase (Figure 3 ).

\section{Effect of Solvents}

Two solvents commonly used to dissolve drugs (DMSO and ethanol) were tested for their effect on the SPA counts. It was determined that the specific signal decreased as the concentration of ethanol or DMSO concentration was increased above 1\% (Figure 4). 


\section{Determination of Colchicine Dissociation Constant of Binding $\left(K_{d}\right)$ to Tubulin}

The $\mathrm{K}_{\mathrm{d}}$ for colchicine binding to tubulin was determined by increasing the concentration of radioligand $(0.005$ $-2.6 \mu \mathrm{M})$ with a constant amount of tubulin $(0.5 \mu \mathrm{g})$. GraphPad Prism was used to determine the $\mathrm{B}_{\max }$ (total receptor number) and $\mathrm{K}_{\mathrm{d}}$ using nonlinear regression to fit the data to a one-site binding curve using the formula

specific binding $=\frac{\mathrm{B}_{\max } \times[\mathrm{L}]}{\mathrm{K}_{\mathrm{d}}+[\mathrm{L}]}$

$$
\mathrm{K}_{\mathrm{d}}+[\mathrm{L}]
$$

where [L] is the concentration of free radioligand, $\mathrm{B}_{\max }$ is the total number of

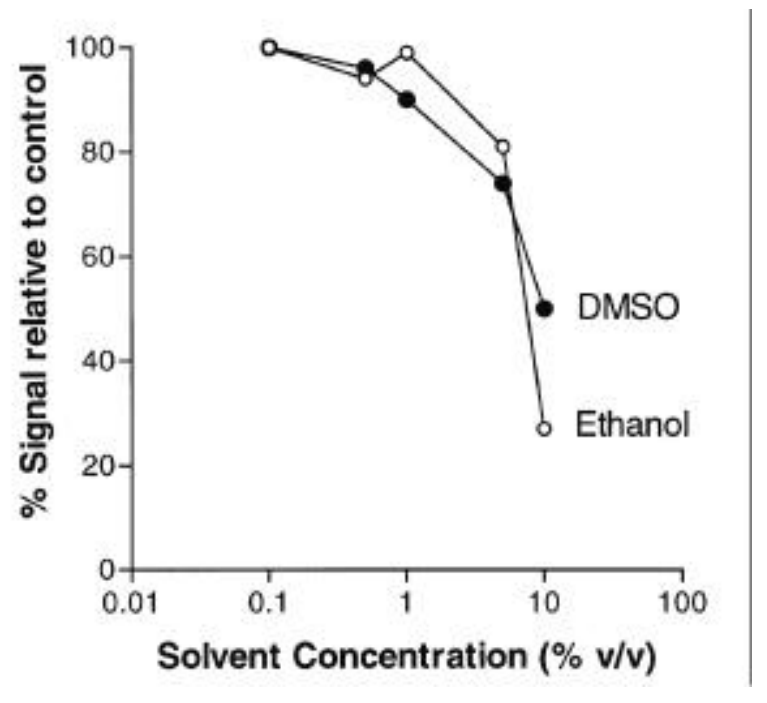

Figure 4. Effect of solvents. $\left[{ }^{3} \mathrm{H}\right]$ colchicine was incubated with biotin-tubulin for $1 \mathrm{~h}$ with or without varying concentrations of solvent. The specific counts in the presence of solvent was determined and expressed relative to the specific counts in the controls. A DMSO or ethanol concentration at or below $1 \%$ did not adversely affect the assay.

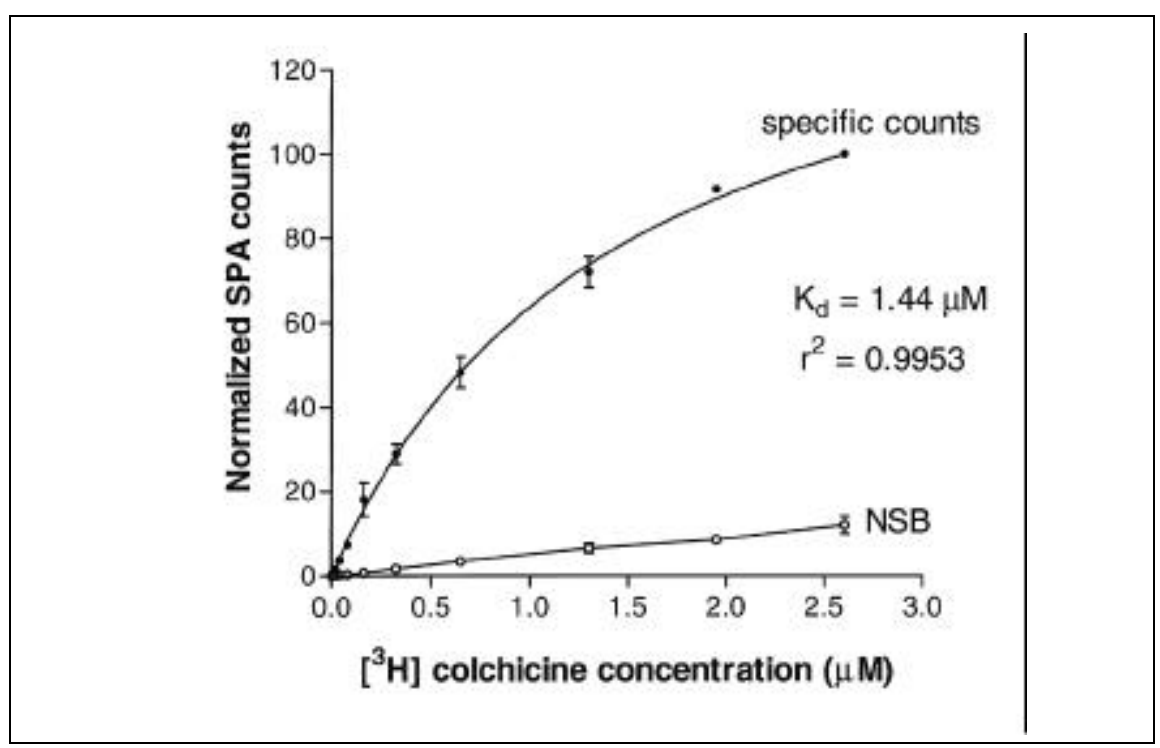

Figure 5. Determination of colchicine dissociation constant of binding $\left(\mathbf{K}_{d}\right)$ to tubulin. The $K_{d}$ for colchicine binding to tubulin was determined by increasing the concentration of radioligand with a constant amount of tubulin $(0.5 \mu \mathrm{g})$. Nonlinear regression was used to analyze the data using GraphPad Prism. Data represents mean \pm SD. 
receptors expressed in the same units as specific binding and $\mathrm{K}_{\mathrm{d}}$ is the equilibrium dissociation constant (expressed in the same units as [L]).

The binding of colchicine to tubulin was saturable (Figure 5). The $\mathrm{K}_{\mathrm{d}}$ for colchicine under our experimental conditions was $1.4 \mu \mathrm{M}$, which was consistent with previously reported values $(16,20)$. NSB increased in a linear manner as the concentration of radioligand was increased, and background accounted for only $3 \%-10 \%$ of the total counts. The portion of the curve to the right showing binding at higher radioligand concentrations did not reach complete saturation. We did not go higher because of the expense of the radioligand and the NSB might be too high a fraction of total binding.

\section{Inhibition of Colchicine Binding to Tubulin}

Validation of the assay was performed by competitively inhibiting $\left[{ }^{3} \mathrm{H}\right]$ colchicine binding to tubulin with known microtubule inhibitors and comparing their $\mathrm{K}_{\mathrm{i}}$ values when possible. The competition assays were performed by holding the protein and radioligand concentrations constant and varying the concentration of the unlabeled competitor. The $\mathrm{K}_{\mathrm{i}}$ values for each compound were used to compare their effect on colchicine binding since $\mathrm{IC}_{50}$ values tend to vary between laboratories because of the different methodologies used and variation in radioligand concentration. $\mathrm{K}_{\mathrm{i}}$ values were calculated using the Cheng-Prussof equation (6). Nonlinear regression analysis was used to fit the data to a onesite competition-binding curve using GraphPad Prism. The $K_{i}$ values for combretastatin A4, E7010, podophyllotoxin, mebendazole, colcemid and colchicine, reported to bind to tubulin at the colchicine site range between $0.2-4.6 \mu \mathrm{M}$, are listed in Table 1. Taxol and vinblastine, which bind to different sites on tubulin, did not compete with $\left[{ }^{3} \mathrm{H}\right]$ colchicine binding to tubulin at concentrations below $100 \mu \mathrm{M}$. The values of various microtubule inhibitors in our SPA assay were consistent with $\mathrm{K}_{\mathrm{i}}$ values reported by others (Table 1).

In summary, our assay is useful for evaluating antimitotic compounds in vitro and can overcome the disadvantage of traditional filtration techniques since there are no separation steps. Our SPA bead method is extremely easy to set up, multiple samples can be assayed, supply and labor costs are minimal and it has utility as a high-throughput screening tool.

\section{REFERENCES}

1.Arai, T. and T. Okuyama. 1975. Fluorometric assay of tubulin-colchicine complex. Anal. Biochem. 69:443-450.

2.Basu, A. and S. Haldar. 1998. Microtubuledamaging drugs triggered bcl2 phosphorylation-requirement of phosphorylation on both serine- 70 and serine- 87 residues of bcl 2 protein. Int. J. Oncol. 13:659-664.

3.Bershadsky, A.D. and J.M. Vasiliev. 1989. Cytoskeleton. Plenum Press, New York.

4.Blagosklonny, M.V., P. Giannakakou, W.S. El-Deiry, D.G.I. Kingston, P.I Higgis, L. Neckers and T. Fojo. 1997. Raf-1/bcl2 phosphorylation: a step from microtubule damage to cell death. Cancer Res. 57:130-135.

5.Borisy, G.G. 1972. A rapid method for quantitative determination of microtubule protein using DEAE-cellulose filters. Anal. Biochem. 50:373-385.

6.Cheng, Y. and W.H. Prusoff. 1973. Relationship between the inhibition constant $\left(\mathrm{K}_{\mathrm{i}}\right)$ and the concentration of an inhibitor which causes 50 per cent inhibition $\left(\mathrm{I}_{50}\right)$ of an enzymatic reaction. Biochem. Pharmacol. 22:3099-3108.

7.Chaplin, D.J., G.R. Pettit and S.A. Hill. 1999. Anti-vascular approaches to solid tumour therapy: evaluation of combretastatin A4 phosphate. Anticancer Res. 19:189-195.

8.Detrich, H.W., III, S.A. Berkowitz, H. Kim and R.C. Williams, Jr. 1976. Binding of glycerol by microtubule protein. Biochem. Biophys. Res. Commun. 68:961-968.

9.Dustin, P. 1984. Microtubules. Springer-Verlag, Berlin.

10.Garland, D. 1978. Kinetics and mechanism of colchicine binding to tubulin. Evidence for ligand-induced conformational change. Biochemistry $17: 4266-4271$.

11.Hamel, E. 1996. Antimitotic natural products and their interactions with tubulin. Biochemistry 16:207-231.

12.Hyams, J.S. and C.W. Lloyd. 1994. Microtubules. Wiley-Liss, New York.

13.Jordan, M.A., J.A. Hadfield, N.J. Lawrence and A.T. McGown. 1998. Tubulin as a target for anticancer drugs: agents which interact with the mitotic spindle. Med. Res. Rev. 18:259-296.

14.Jordan, M.A. and L. Wilson. 1998. Microtubules and actin filaments: dynamic targets for cancer chemotherapy. Curr. Opin. Cell Biol. 10:123-130.

15.Jordan, M.A. and L. Wilson. 1998. Use of drugs to study role of microtubule assembly dynamics in living cells. Methods Enzymol. 298:252-276.

16.Kelleher, J.K. 1977. Tubulin binding affinities of podophyllotoxin and colchicine analogues. Mol. Pharmacol. 13:232-241.
17.Lambier, A. and Y. Engelborghs. A quantitative analysis of tubulin-colchicine binding to microtubules. 1980. Eur. J. Biochem. 109:619624.

18.Liliom, K., A. Lehotzky, A. Molnar and J. Ovadi. 1995. Characterization of tubulin-alkaloid interactions by enzyme-linked immunosorbent assay. Anal. Biochem. 228:18-26.

19.Lin, C.M., H.H. Ho, G.R. Pettit and E. Hamel. 1989. Antimitotic natural products combretastatin A-4 and Combretastatin A-2: studies on the mechanism of their inhibition of the binding of colchicine to tubulin. Biochemistry 28:69846991.

20.Luyckx, M., C. Brunet and M. Cazin. 1984. Binding of colchicine to beef brain tubulin: influence of methodology on binding constants. Methods Find. Exp. Clin. Pharmacol. 6:679684.

21.Nogales, E., S.G. Wolf and K.H. Dowing. 1998 . Structure of the $\alpha \beta$ tubulin dimer by electron crystallography. Nature 391:199-202.

22.Ray, K., B. Bhattacharyya and B.B. Biswas. 1981. Role of B-ring of colchicine in its binding to tubulin. J. Bio. Chem. 256:6241-6244.

23.Russell, G., J.H. Gill and E. Lacey. 1992. Binding of $[3 \mathrm{H}]$ benzimidazole carbamates to mammalian brain tubulin and the mechanism of selective toxicity of the benzimidazole anthelmintics. Biochem. Pharmacol. 43:10951100 .

24.Sherline, P., C.K. Bodwin and D.M. Kipnis. 1974. A new colchicine binding assay for tubulin. Anal. Biochem. 62:400-407.

25.Sweetnam, P.M., L. Caldwell, J. Lancaster, C. Bauer, Jr., B. McMillan, W.J. Kinnier and C.H. Price. 1993. The role of receptor binding in drug discovery. J. Natural Products 56:441455.

26.Valdivia, M. and B.R. Brinkley. 1984. Biochemical studies of the kinetochore/centromere of mammalian chromosomes, p. 79-86. In G.G. Borisy, D.W. Cleveland and D.B. Murphy (Eds.), Molecular Biology of the Cytoskeleton. CSH Laboratory Press, Cold Spring Harbor, New York.

27.Wilson, L. and K.W. Farrell. 1986. Kinetics and steady state dynamics of tubulin addition and loss at opposite microtubule ends:the mechanism of action of colchicine. Ann. NY Acad. Sci. 466:690-708.

28. Yamamoto, K., K. Noda, A. Yoshimura, M. Fukuoka, K. Furuse and H. Niitani. 1998. Phase I study of E7010. Can. Chemother. Pharmacol. 42:127-134

29.Yoshimatsu, K., A. Yamaguchi, H. Yoshino, N. Koyanagi and K. Kitoh. 1997. Mechanism of action of E7010, an orally active sulfonamide antitumor agent: inhibition of mitosis by binding to the colchicine site of tubulin. Cancer Res. 57:3208-3213.

Received 18 October 1999; accepted 10 February 2000.

Address correspondence to:

Dr. Shi-Chung Ng

Abbott Laboratories

Dept. 4N6, AP9-2

100 Abbott Park Rd

Abbott Park, IL 60064, USA

e-mail: shi-chung.c.ng@abbott.com 